\title{
Surgical Correction of Cardiac Defects with Ellis Van Crevald Syndrome - A Rare Case Report
}

\author{
DIR Choudhury, MS, ${ }^{1}$ Saikat DasGupta, MS, ${ }^{2}$ Mauin Uddin, MS, ${ }^{3}$ Siddhartha Shankar Howlader, MS, ${ }^{1}$ \\ PK Chanda, MS, ${ }^{2}$ Professor A.T.M. Khalilur Rahman, DA, ${ }^{4}$ Professor Farooque Ahmed, MS $^{1}$ \\ ${ }^{1}$ Department of Cardiac Surgery, National Heart Foundation Hospital \& Research Institute, Dhaka, Bangladesh; ${ }^{2}$ Department of \\ Cardiac Surgery, Square Hospital Limited, Dhaka, Bangladesh; ${ }^{3}$ Registrar-Department of Cardiothoracic Surgery, Liverpool Heart and \\ Chest Hospital, UK; ${ }^{4}$ Department of Cardiac Anesthesia, National Heart Foundation Hospital \& Research Institute, Dhaka, Bangladesh
}

\section{ABSTRACT}

Ellis-Van Creveld (EVC) syndrome is an autosomal recessive disorder. Around 150 cases are described in published literature and in Bangladesh, it is even rare. The patient usually comes with short stature, dental deformity, and cardiac deformity. Here, we present the case of a patient with ostium primum atrial septal defect (ASD) with moderate mitral regurgitation who underwent surgical repair of ASD and mitral valve replacement.

\section{INTRODUCTION}

Ellis-Van Creveld syndrome, also known as chondroectodermal dysplasia, is a rare autosomal recessive disorder [RuizPerez 2000] with the incidence of 1:244,000 of the entire population [Ellis 1940]. The exact prevalence is unknown, but the syndrome seems more common among the Amish community [Baujat 2007]. Not more than 25 cases have been reported in India [Shetty 2015] and in Bangladesh it is rarely diagnosed.

EVC syndrome first was described by physicians Richard WB Ellis (1902-1966) of Edinburgh, Scotland, and Simon van Creveld (1895-1971) of Amsterdam, Netherlands. In the late 1930 s, these two pediatricians while traveling to a pediatrics conference in England met on a train and discovered that each had a patient with a similarly distinctive phenotype [Ellis 1940].

This disorder is characterized by a tetrad of clinical manifestations of chondrodysplasia, postaxial polydactyly, ectodermal dysplasia, and congenital cardiac defects [Ruiz-Perez 2003]. In this case report, we are presenting the case of a patient who underwent surgical correction for atrial septal defect (ASD) with mitral regurgitation (MR).

Received September 9, 2020; accepted November 1, 2020

Correspondence: Mauin Uddin, Cardiothoracic Surgery, Liverpool Heart and chest Hospital, UK (e-mail: mu_abmed07@yahoo.com).

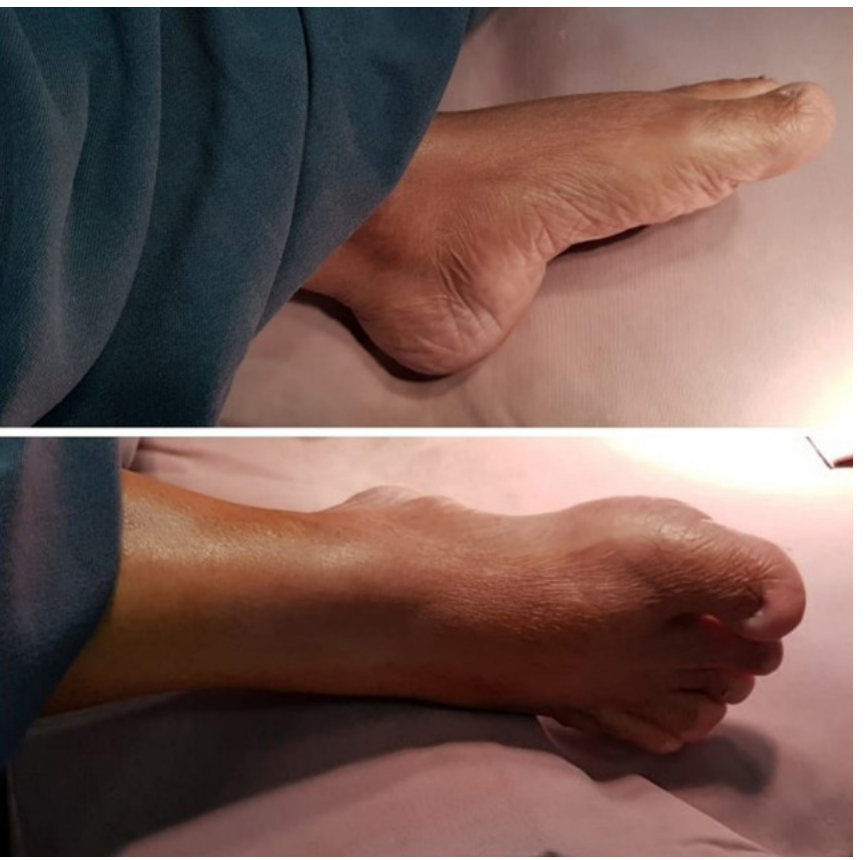

Figure 1. Short lower limbs
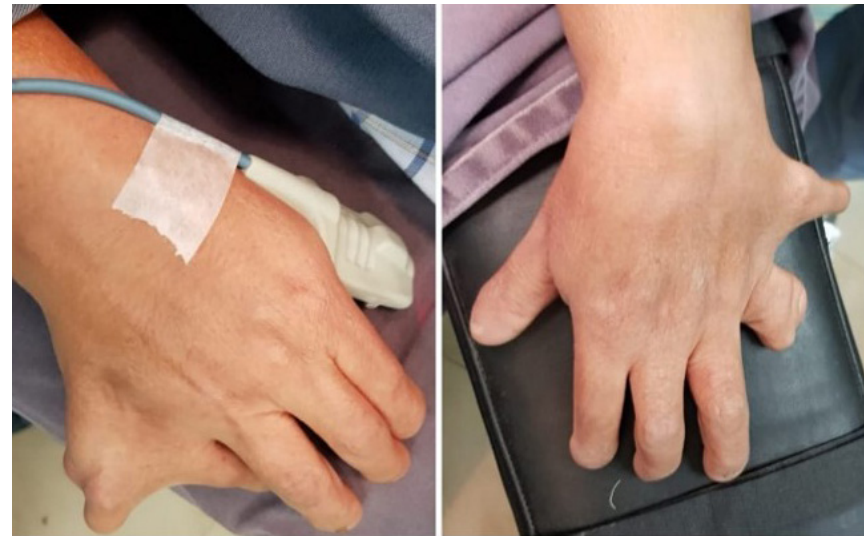

Figure 2. Six fingers on each hand. The sixth digit is seen at the medial aspect of the hands (post axial polydactyly). 


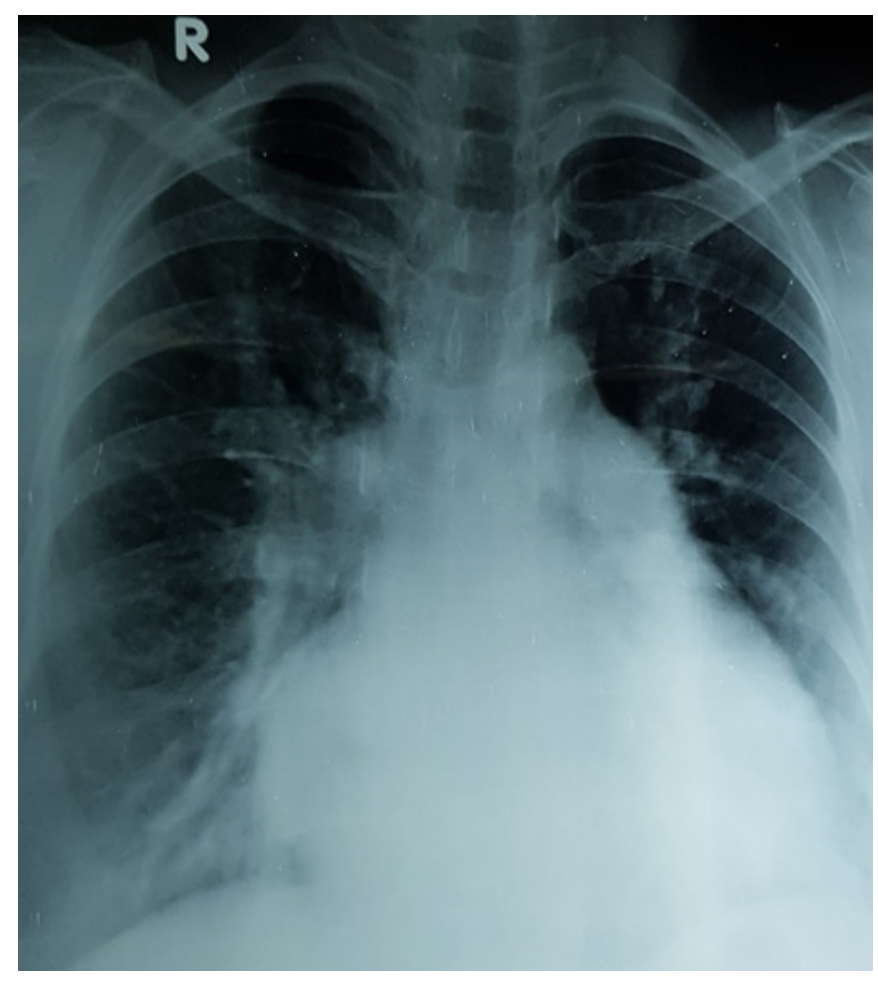

Figure 3. X-ray chest PA view showing cardiomegaly with features of shunt anomaly.

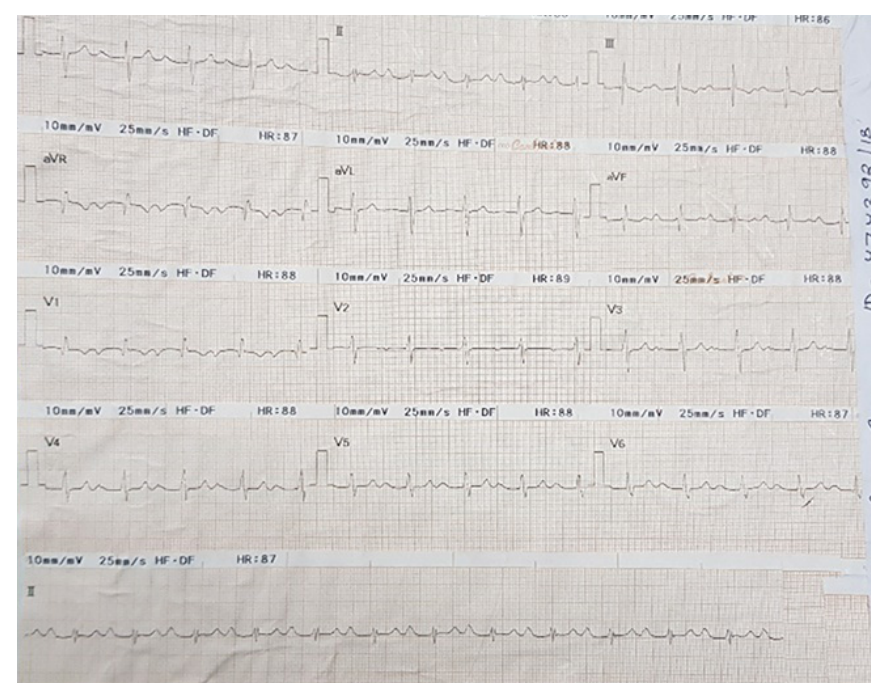

Figure 4. Preoperative ECG

\section{CASE REPORT}

A 40-year-old female patient hailing from Sylhet (Mountain area) presented with a history of few months of progressive worsening shortness of breath and palpitation. Her NYHA class was II-III. She had no significant co-morbidities.

On examination, she was short-statured compared to her age. Her lower limbs were relatively short. (Figure 1) Her
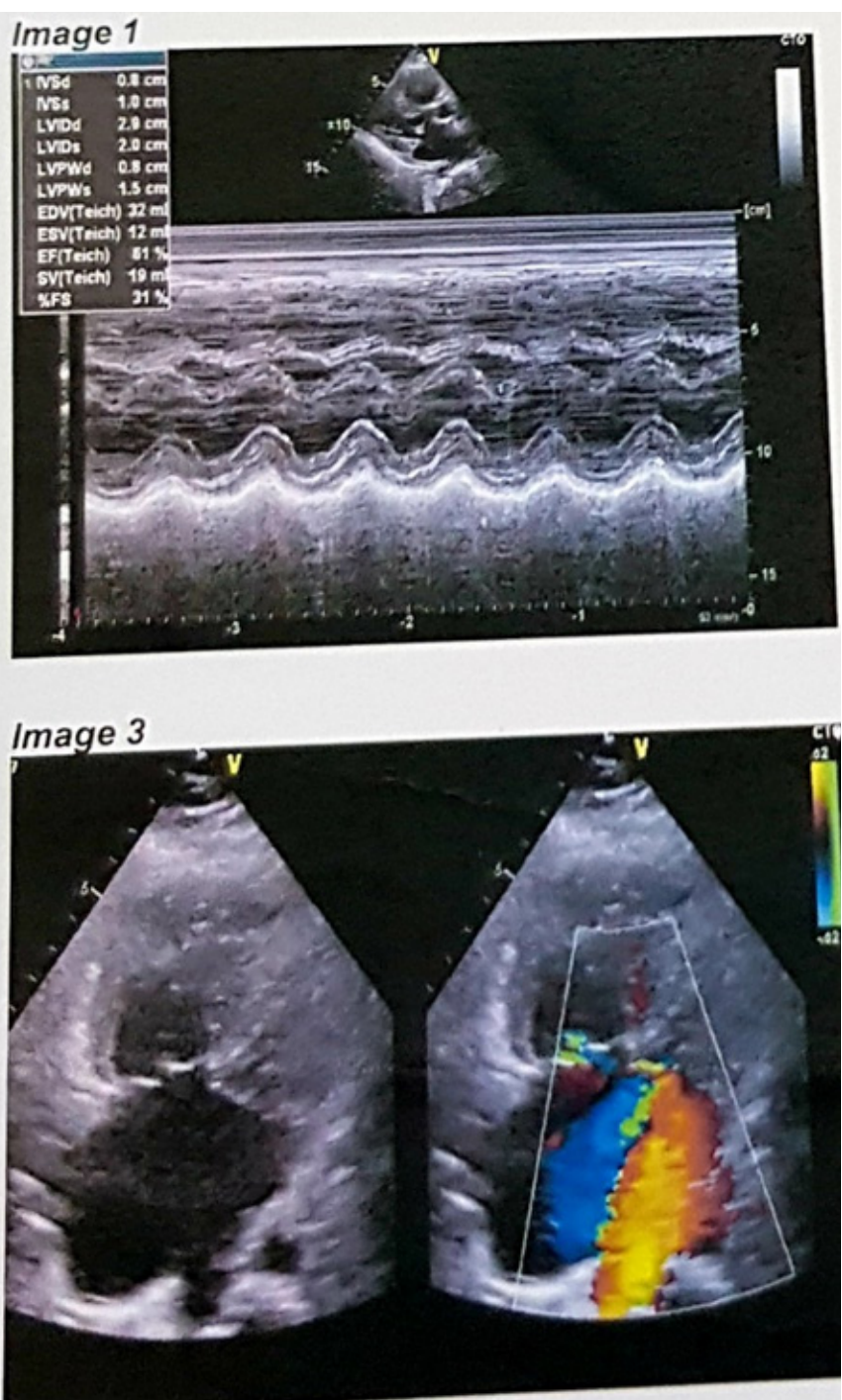

Figure 5. Echocardiogram showing MR

upper limbs showed an extra finger on each hand. (Figure 2) Her teeth were disorganized; some teeth were missing. Cardiac examination revealed systolic murmur in the pulmonary and mitral area.

On further questioning, she mentioned that her brother also had a similar body habitus without any cardiac anomaly. All preoperative blood results were within standard limits, with the exception of NTproBNP $(682 \mathrm{pg} / \mathrm{ml})$. X-ray chest had features of cardiomegaly and pulmonary congestion. (Figure 3) Lung function test was normal.

Transthoracic echocardiography showed a large primum ASD (about $34 \mathrm{~mm}$ in diameter) with L- R shunt. (Figure 6) Moreover, there was moderate MR, due to a suspected cleft in the anterior mitral leaflet (AML). (Figure 5) Vena contracta was measured at 0.6 , and there was a jet area of $40 \%$ along with mild TR \& PAH (PASP $58 \mathrm{~mm} \mathrm{Hg}$ ). Paradoxic IVS with good ventricular function and dilated right chambers of the heart were found. 


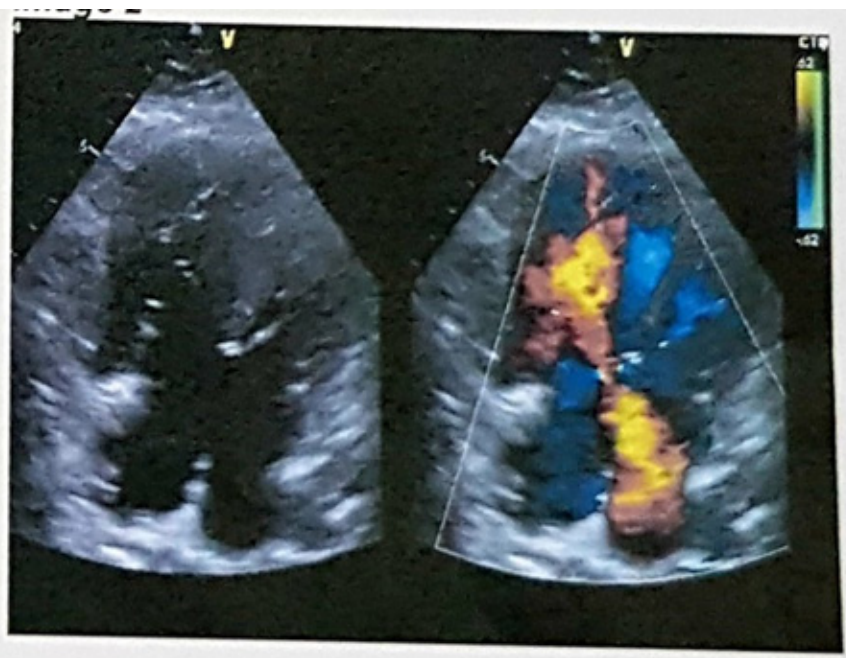

Image 4

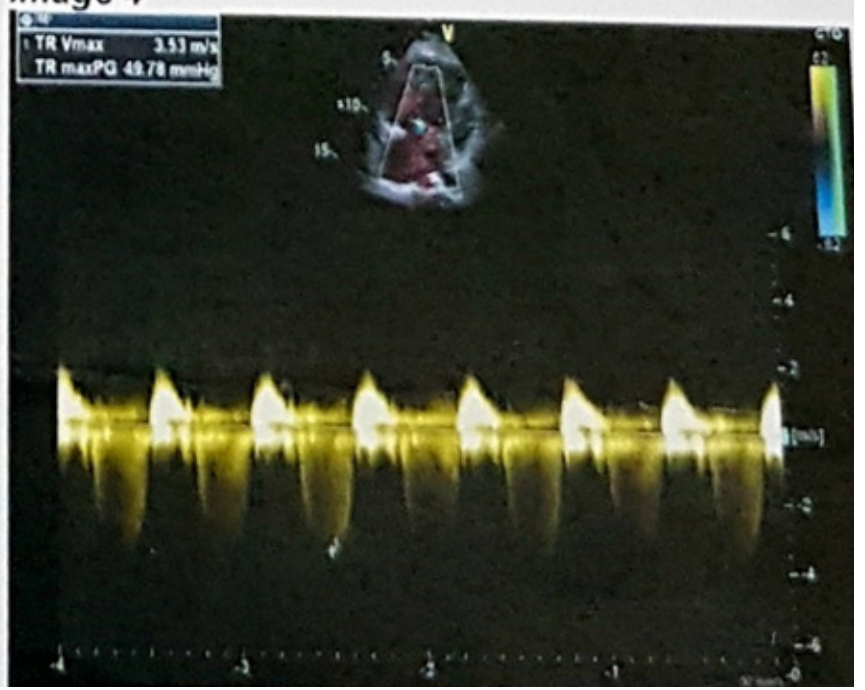

Figure 6. Echocardiogram showing AV canal defect with MR

ECG revealed prolonged PR interval and pathological Q waves in lead III and aVF with heart rate $86 \mathrm{~b} / \mathrm{min}$. (Figure 4) USG of the abdomen was negative for any findings relating to this syndrome.

CT coronary angiogram showed non-critical coronary artery lesion. Chest CT also was negative for any other abnormality. With all these clinical and radiological findings, she was diagnosed with Ellis-Van Creveld syndrome. We discussed this case in our heart team meeting. All members agreed with the diagnosis and need for surgery to correct her cardiac defects.

Operative findings: After a brief discussion with the patient and written informed consent, she was scheduled for the open-heart procedure. Intraoperative transesophageal echocardiography (TEE) showed primum variety ASD (Figure 7) and moderate to severe MR because of the cleft in AML. (Figure 7) No other congenital anomaly and valvular abnormalities were identified. She was prepared for

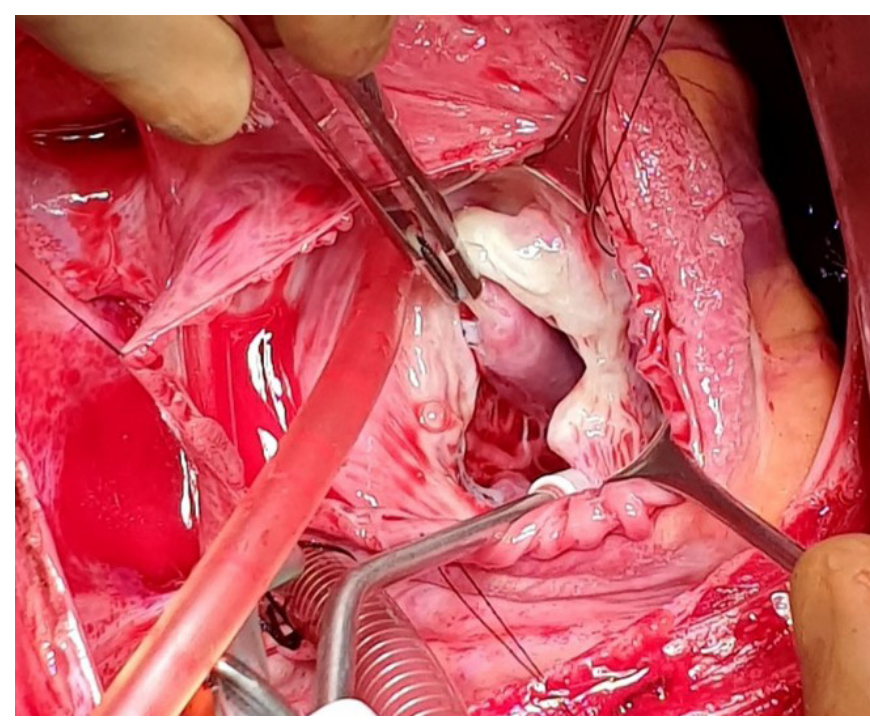

Figure 7. Cleft in the AML seen through ASD

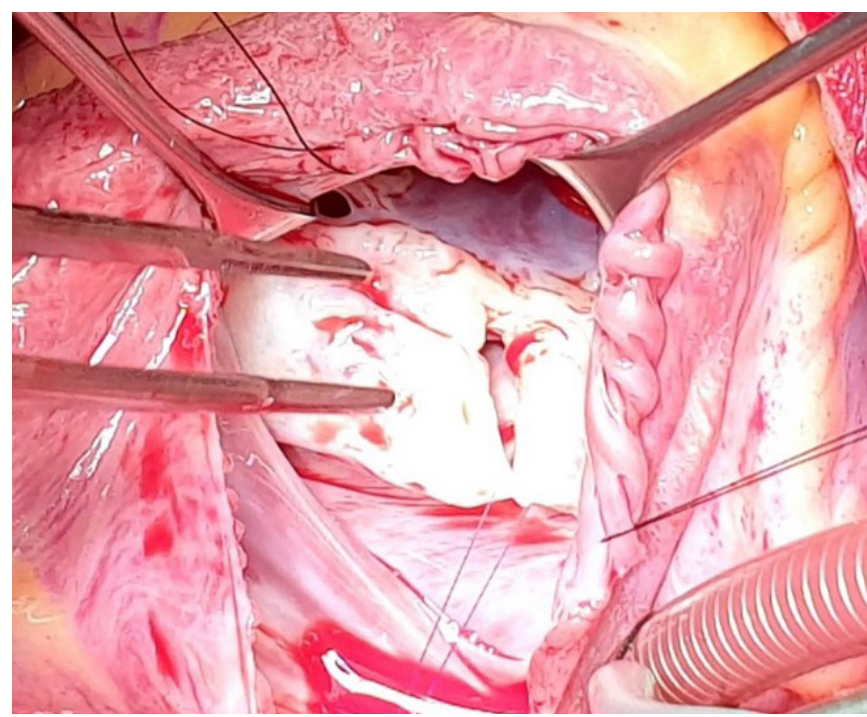

Figure 8. Ongoing cleft repair through ASD

standard open-heart procedure with bi-caval and aortic cannulation.

Pericardial patch was harvested and treated with a glutaraldehyde solution. On opening of the right atrium, ASD was identified. However, all four pulmonary veins were found draining to the LA. The mitral valve was checked, and a cleft was found in AML. The cleft was repaired with interrupted 6-0 prolene but the result was not satisfactory as evident by saline test. So the mitral valve was replaced with a 27 SJM mechanical valve. The ASD was closed with a glutereldehyde treated pericardial patch. (Figure 8) (Figure 9) (Figure 10)

The right atrium was closed. TEE confirmed no defect in the atrial septum, stable prosthetic valve in the mitral position, and good biventricular function. 


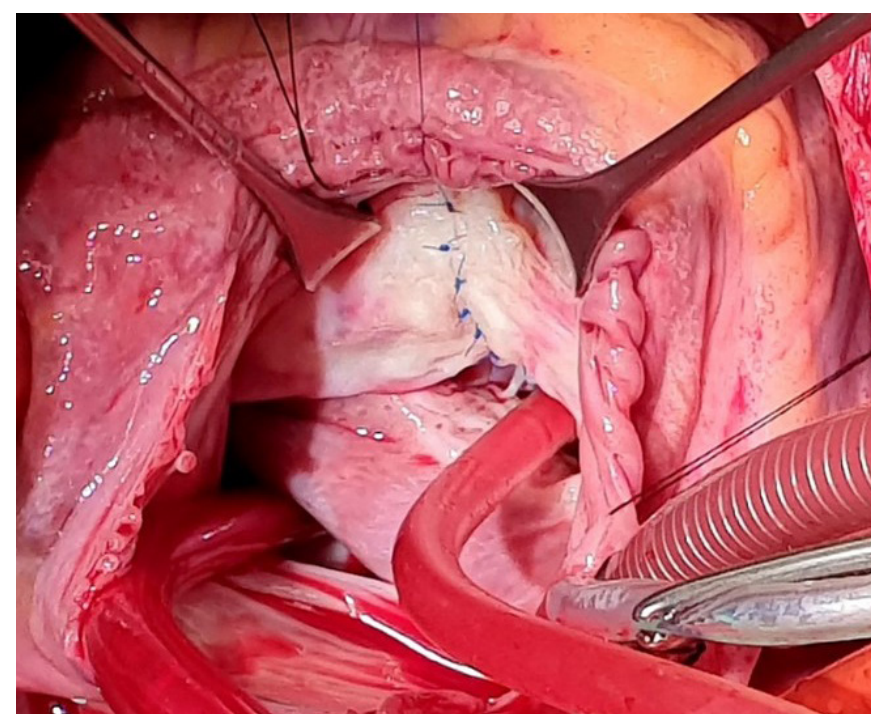

Figure 9. Initial repaired cleft

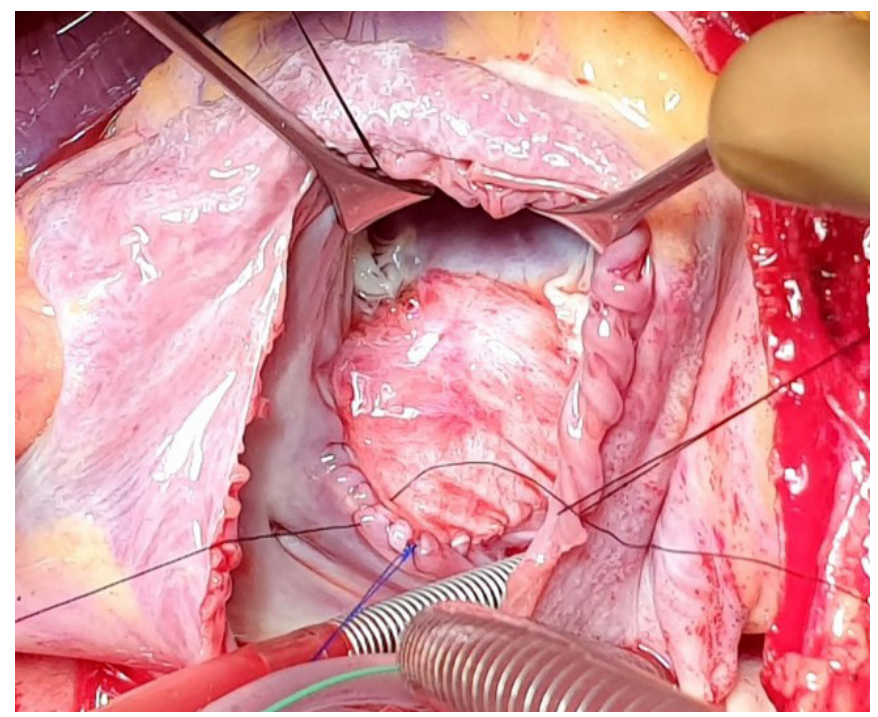

Figure 10. ASD closure with pericardial patch

She was weaned off from CBP with minimum inotropes. The patient was transferred to the ICU with stable hemodynamics. She was extubated the next morning, and her subsequent post-operative days were uneventful.

She remained in sinus rhythm in the postoperative period. (Figure 11) Prior to her discharge, transthoracic echocardiography demonstrated satisfactory results. The patient was discharged on postoperative day 6 , with warfarin, low dose diuretics and a beta blocker.

\section{DISCUSSION}

All three embryonic layers appear involved in Ellis-Van Creveld syndrome [Biggerstaff 1968]. The signs of ectodermal

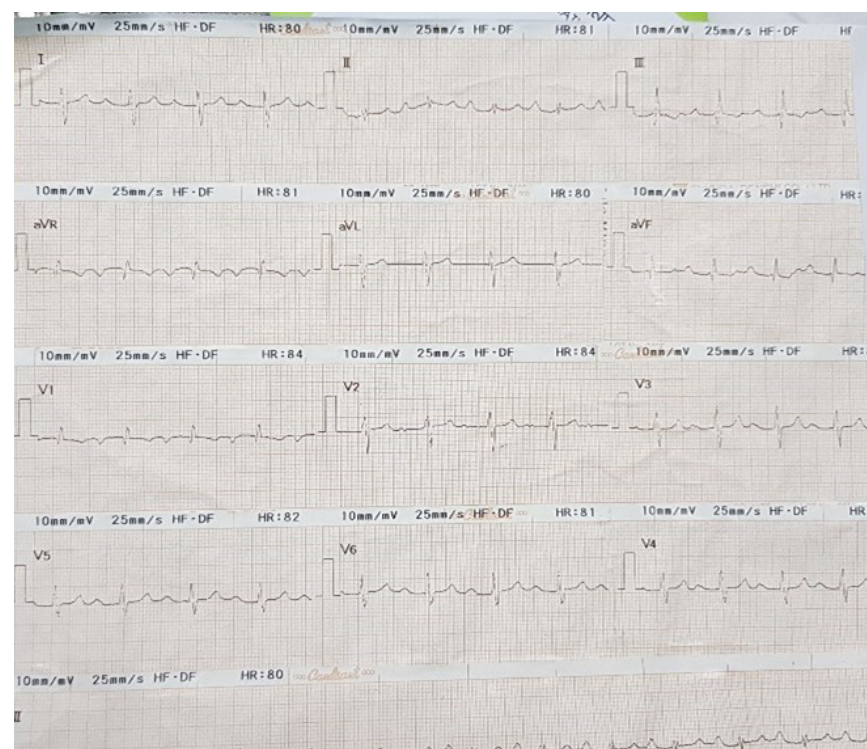

Figure 11. Postoperative ECG

dysplasia are usually limited to nails, teeth, and gums. Endodermal involvement is not very common but sometimes affects the liver and lungs. Abnormalities of the heart and kidneys indicate mesodermal involvement [Sajeev 2002].

Chondrodysplasia is characterized by a disproportionate small stature (mesomelic dwarfism) and a variety of skeletal anomalies of which polydactyly is the most common [Blackburn 1971].

Facial abnormalities, such as partial harelip, maxillary alveolar clefts, abnormal tooth shape, number of missing teeth/ fused teeth, and site of implantation (disorderly arranged and improperly spacing). There also could be multiple labial frenum, obliteration of the labiogingival sulcus are all pathognomonic and should be used in primary diagnosis [Popli 2002].

Cardiac anomalies are found in $50-60 \%$ of patients with a common atrium and persistent atrioventricular (AV) canal being the most common defects [Grainger 1992]. Other pathology, such as persistent ductus arteriosus (PDA), ventricular septal defects (VSD), and atrial septal defects (ASD) also could be present.

Valvular and shunt defects (PDA, ASD, VSD) are some of the malformations described as the principal cause of decreased life-expectancy in these patients [Baujat 2007; Arya 2001; Katsouras 2003; Alves-Pereira 2009].

Genitourinary anomalies, such as agenesis and renal dysplasia, ureterectasia and nephrocalcinosis, account for $20 \%$ of cases [Alves-Pereira 2009]. Other uncommon anomalies seen are strabismus, congenital cataracts, cryptorchidism, and epi and hypospadias [Digoy 2005; Ghosh 2007].

Radiological features comprise a narrow thoracic cage and wide, spade-like anterior ends, square iliac ala and "trident acetabulum" in the pelvis. Other features are shortened long bones in the extremities, with wide diaphyses and metaphyses.

Diagnosis at birth can be made by observing the typical symptoms of the disease. Skeleton radiography, ECG, and echocardiography also may help in the diagnosis of EVC syndrome. 
The definitive diagnosis is made by molecular diagnostic methods, based on homozygosity for a mutation in the EVC1 and EVC2 genes by direct sequencing [Ghosh 2007]. The patient had ultrasound scanning during fetal life, but no diagnosis was made. Genetic counseling was not done, so prenatal evaluation for a second baby was not done. One-third of these patients die at an early age or in infancy from cardiorespiratory problems.

EVC syndrome should be differentially diagnosed from two conditions with overlapping features like asphyxiating thoracic dystrophy (jeune syndrome) and short rib polydactyly syndrome. The central feature of asphyxiating thoracic dystrophy is a small chest that appears long and narrow. The main distinguishing feature is the absence of hypoplastic nails of hands and feet and asymmetrical presence of polydactyly, but in EVC syndrome symmetrical presence of polydactyly and hypoplastic nails are noted. The other condition, which should be considered due to common features, is short rib polydactyly syndrome. It is characterized by underdeveloped lungs, polydactyly, cleft lip and palate, and kidney and intestinal malformations. But in the present case, the lungs, kidney and intestine were normal [Kurian 2007].

Treatment usually is symptomatic accomplished with a multidisciplinary approach of the pulmonologist, cardiologist, cardiac surgeon, orthopedist, physiotherapist, plastic surgeon, dental specialist, and psychologist [Ghosh 2007]. The present case was referred for further dental aesthetic rehabilitation.

We think in our case the cause of the AML cleft repair failed due to a large annulus. We probably should have reduced the mitral valve annulus as well, along with the cleft repair to reduce the mitral regurgitation.

Previously there was a case report of an eight-month-old male child with EVC from same region of Bangladesh was published in 2016, [Ashith 2016].

\section{CONCLUSION}

This is one of the rare autosomal recessive disorders with variable expression, diagnosed by its characteristic clinical manifestations. Skeletal manifestations are definitive and play a vital role in the early diagnosis and treatment planning. It has high mortality in early life, due to cardiac complications. Those who survive require a multidisciplinary approach, mainly for cardiac treatment and rehabilitation. Early diagnosis and treatment can help the patient to prevent various problems and undue psychological and social trauma.
REFERENCES

Alves-Pereira D, Berini-Aytés L, Gay-Escoda C. 2009. Ellis-van Creveld syndrome. Case report and literature review. Med Oral Patol Oral Cir Bucal. 14(7):E340-E343. Jul 1.

Arya L, Mendiratta V, Sharma RC, Solanki RS. 2001. Ellis-van Creveld Syndrome: a report of two cases. Pediatr Dermatol. 18(6):485-489.

Das AC, Azad MT, Chowdhury JF. Ellis-Van Creveld Syndrome: A Case Report. Bangladesh J Child Health 2016; vol 40(3): 179-182.

Baujat G, Le Merrer M. 2007. Ellis-van Creveld syndrome. Orphanet J Rare Dis. 2:27. Jun 4.

Biggerstaff RH, Mazaheri M. 1968. Oral manifestations of the Ellis-van Creveld syndrome. The Journal of American the Dental Association. 77:1090-5.

Blackburn MG, Belliveau RE. 1971. Ellis-van Creveld syndrome.A report of previously undescribed anomalies in two siblings. American Journal of Diseases of Children. 122:267-70.

Digoy GP, Greenberg M, Magit A. 2005. Congenital stridor secondary to an upper airway cyst in a patient with Ellis-van Creveld syndrome. Int J Pediatr Otorhinolaryngol. 69:1433-5.

Ellis RW, van Creveld S. 1940. A syndrome characterized by ectodermal dysplasia, polydactyly, chondro-dysplasia and congenital morbus cordis: Report of three cases. Archives of Disease in Childhood. 15:65-84.

Ghosh S, Setty S, Sivakumar A, Pai KM. 2007. Report of a new syndrome: focus on differential diagnosis and review of Ellis-van Creveld, Curry-Hall, acrofacialdysostosis, and orofacial digital syndromes. Oral Surg Oral Med Oral Pathol Oral Radiol Endod May;103(5):670-676.

Grainger RG, Allis DJ. 1992. Diagnostic Radiology. 11th ed. III. China: Chruchill Living Stone; pp. 651-2.

Katsouras CS, Thomadakis C, Michalis LK. 2003. Cardiac Ellis-van Creveld syndrome. International Journal of Cardiology. Feb;87(2-3):315-316.

Kurian K, Shanmugam S, Harsh Vardah T, Gupta S. 2007. Chondroectodermal dysplasia (Ellis van Creveld syndrome): a report of three cases with review of literature. Indian J Dent Res. 18: 31-34.

Popli MB, Popli V. 2002. EVC syndrome. Indian Journal of Radiology. $12: 549-50$.

Ruiz-Perez VL, Ide SE, Strom TM, Lorenz B, Wilson D, Woods K, et al. 2000. Mutations in a new gene in Ellis-van Creveld syndrome and Weyers acrodental dysostosis. Nature Genetics. 24:pp283-6.

Ruiz-Perez VL, Tompson SW, Blair HJ, Espinoza-Valdez C, Lapunzina P, Silva EO, et al. 2003. Mutations in two nonhomologous genes in a head-to-head configuration cause Ellis-van Creveld syndrome. American Journal of Human Genetics. 72:pp728-32.

Sajeev CG, Roy TN, Venugopal K. 2002. Images in cardiology: Common atrium in a child with Ellis-Van Creveld syndrome. Heart. 88:142.

Shetty P, Shetty D, Priyadarshana PS, Bhat S. 2015. A rare case report of Ellis Van Creveld syndrome in an Indian patient and literature review. J Oral Biol Craniofac Res. 5(2):98-101. 